\title{
Evaluating Arguments for the Sex/Gender Distinction
}

\section{Tomas Bogardus ${ }^{1}$}

Received: 11 July 2019 /Revised: 13 December 2019 / Accepted: 16 December 2019

Published online: 27 January 2020

(C) Springer Nature B.V. 2020

\begin{abstract}
Many philosophers believe that our ordinary English words man and woman are "gender terms," and gender is distinct from biological sex. That is, they believe womanhood and manhood are not defined even partly by biological sex. This sex/ gender distinction is one of the most influential ideas of the twentieth century on the broader culture, both popular and academic. Less well known are the reasons to think it's true. My interest in this paper is to show that, upon investigation, the arguments for the sex/gender distinction have feet of clay. In fact, they all fail. We will survey the literature and tour arguments in favor of the sex/gender distinction, and then we'll critically evaluate those arguments. We'll consider the argument from resisting biological determinism, the argument from biologically intersex people and vagueness, the argument from the normativity of gender, and some arguments from thought experiments. We'll see that these arguments are not up to the task of supporting the sex/ gender distinction; they simply don't work. So, philosophers should either develop stronger arguments for the sex/gender distinction, or cultivate a variety of feminism that's consistent with the traditional, biologically-based definitions of woman and man.
\end{abstract}

Keywords feminism $\cdot$ sex/gender distinction $\cdot$ gender $\cdot$ transgender $\cdot$ trans $\cdot$ ameliorative inquiry $\cdot$ conceptual engineering $\cdot$ biological determinism $\cdot$ biological sex

\section{Introduction}

\subsection{The Traditional Definitions of 'Woman' and 'Man'}

Since at least the middle of the twentieth century, psychologists, psychiatrists, sociologists, and philosophers have put forward a distinction between sex and gender. The

Tomas Bogardus

tbogardus@gmail.com

Extended author information available on the last page of the article 
term gender they borrowed from linguistics, and stipulated that it refer to something other than sex, typically the social features of sex, i.e. the social norms and roles that a culture associates with biological sex. ${ }^{1}$ I do not mean to challenge any such stipulative definition; stipulative definitions can't be false. However, many philosophers have gone further and claimed that our ordinary English terms man and woman are gender terms in a novel, stipulated sense of gender. ${ }^{2}$ This is the idea that I wish to investigate. ${ }^{3}$

Here's how Mari Mikkola $(2016,23)$ expresses the sex/gender distinction:

Speakers ordinarily seem to think that 'gender' and 'sex' are coextensive: women and men are human females and males, respectively, and the former is just the politically correct way to talk about the latter. Feminists typically disagree and many have historically endorsed a sex/gender distinction. Its standard formulation holds that 'sex' denotes human females and males, and depends on biological features (chromosomes, sex organs, hormones, other physical features). Then again, 'gender' denotes women and men and depends on social factors (social roles, positions, behavior, self-ascription).

It is this "standard formulation" of the sex/gender distinction that I wish to evaluate, specifically the claim that "'gender' denotes women and men and depends on social factors." I want to investigate the claim that woman and man are gender terms in a novel, stipulated sense of gender, i.e. the claim that manhood and womanhood are not to be defined even partially in terms of male and female, which refer to biological sex, but rather in terms of something like social position, a particular set of experiences, selfidentification, or the like. This suggestion is in contrast to what I'll call "the traditional definitions" of man and woman, on which these words are defined in terms of biological sex: a woman is an adult female human, and a man is an adult male human. ${ }^{4}$

\footnotetext{
${ }^{1}$ See, for example, psychologists like John Money (1955), Anke Ehrhardt (Money and Ehrhardt 1972), Linda Nicholson (1994), 80) and Robert Stoller (1968), psychiatrists like Richard Green (2010), sociologists like Judith Lorber (1994), and feminist philosophers like Gayle Rubin (1975), Sally Haslanger (2000), and Natalie Stoljar (1995). Though, for dissenting voices who challenge the sex/gender distinction, see Louise Antony (1998), Moira Gatens (1996), Elizabeth Grosz (1994), and Raia Prokhovnik (1999).

${ }^{2}$ Similarly for boy and girl, though for simplicity and readability I will omit these terms in the discussion below.

${ }^{3}$ An anonymous referee helpfully asks me to clarify: "If stipulative definitions can't be false, why does the author want to investigate?" My idea is that, while a novel, stipulative definition of "gender" can't be false, the claim that our ordinary English terms man and woman are gender terms in this novel, stipulative sense of "gender" can be false. For example, we often use a technical, stipulative definition for "valid" in our Logic classes. Since it's stipulative, it can't be false. But if we go on to claim that some particular argument is valid in this stipulative sense, we can certainly be wrong, depending on the argument. Likewise if we claim that our ordinary English term "convincing" means the same thing as "valid" in this technical sense; that too could be false. Another example: if I define "meter" to mean the length of this bar, it can't be false that this bar is a meter long. But it can be false that, for example, my sledgehammer is a meter long, or that the ordinary English word "yard" names the same length that "meter" does, so defined. In a similar way, I mean to challenge the claim that our ordinary English words man and woman pick out genders, in these novel, stipulative senses of "gender."

${ }^{4}$ To say that this is the traditional concept of womanhood is not to deny conceptual connections between this concept and other concepts of norms, identity, expression, or social status. It's only to say that, when exercising this traditional concept of womanhood - when using the "dominant manifest meaning" of the term woman, as Haslanger calls it - to think of, for example, norms about women or acceptable modes of expression for women, is to think of norms about adult human females, and acceptable modes of expression for adult human females.
} 
These traditional definitions were, until recently, universally reported by lexicographers in, for example, the Oxford English Dictionary. The traditional definitions express what Sally Haslanger $(2012,375)$ calls "the dominant manifest meaning" and what Toril Moi (1999), 8) calls "the ordinary understanding" of man and woman, and these traditional definitions are what Talia Mae Bettcher (2009), 103) calls the "definitional account" of gender. As Mikkola (2017) puts it elsewhere, "Most people ordinarily seem to think that sex and gender are coextensive: women are human females, men are human males." On this view, there is no sex/gender distinction, and one's biological sex is determined by biological features like one's gamete size, hormone levels, primary and secondary sex characteristics, and genetics. And perhaps we weight these features according to how central or crucial we take them to be to membership in a biological sex category. ${ }^{5}$

Why call this view "traditional"? Well, the Oxford English Dictionary's first three senses of woman refer to adult female humans, and similarly for man. We're told that the word woman comes from an Old English word wifmann, meaning "female human": wiff (which meant female, not wife) modifying mann (which meant human, generically). To take just one example of an early use, we see that Jane Anger, in her essay Her Protection for Women (1589) used the word like so: "Was there ever any so abused, so slaundered, so railed upon, or so wickedly handeled undeservedly, as are we women?" Even Simone de Beauvoir, in her famous and influential book The Second Sex ([1949] 1956, 15) says, "Woman has ovaries; a uterus..." and later (ibid., 59) she says, “...there have always been women. They are women in virtue of their anatomy and physiology." As late as 1976, de Beauvoir endorsed the traditional definition of woman, saying in an interview, "A positive definition of 'woman'? Woman is a human being with a certain physiology..." (Brison 2003, 192). ${ }^{7}$ Of this traditional definition of womanhood, Bettcher $(2009,105)$ says: "On the face of it, the definition 'female, adult, human being' really does seem right. Indeed, it seems as perfect a definition as one might have

\footnotetext{
${ }^{5}$ Many biologists seem to hold that gamete size is the scientific essence of biological sex, as $\mathrm{H}_{2} \mathrm{O}$ is the scientific essence of water, i.e. to be a female is to belong to the sub-type of a species that produces large, immotile gametes, and similarly for male, though with regard to small, typically motile gametes. Most days, I think they're right about this. To account for cases in which a male is (due to youth, advanced age, "malfunction," etc.) currently unable to produce small, motile gametes, proponents of this definition will likely need to import teleological notions of proper function. And mutatis mutandis with females. Personally, I can't get enough teleology; but those who are allergic may look instead toward more broadly-based criteriaweighting views. For views with a similar criteria-weighting spirit, see Jacob Hale's (1996) first five characteristics of what he calls "the defining characteristics of the category woman," which he thinks exhaust the sex characteristics. He says that these characteristics are, in our culture, more heavily weighted than any other when determining womanhood. See also Iris Young's $(1997,32)$ definition of women in terms of female bodies and biological processes (e.g. menstruation, childbirth, etc.), and gender-coded objects and practices (e.g. pronouns, clothes, cosmetics, etc.).

${ }^{6}$ If that's surprising to you, perhaps that's because, as Sara Heinämaa (1997) argues, de Beauvoir's more famous dictum that "one is not born, but rather becomes, a woman" is commonly misread metaphysically, as endorsing the sex/gender distinction, when really de Beauvoir is interested only in a phenomenological description of women's situation. See also Kate Kirkpatrick (2019), who nicely traces the lineage of de Beauvoir's famous saying back to philosophical debates in the 1920 s, specifically to similar constructions by Maurice Blondel (ibid., 79) and especially Alfred Fouillée's "One isn't born, but rather becomes, free" (ibid., 255), a play on Rousseau's famous line, "Man is born free, and everywhere he is in chains." In that light, Kirkpatrick interprets de Beauvoir's dictum as a claim about the socialization and oppression of women (i.e. adult human females), rather than a revisionary claim about the metaphysics of womanhood.

${ }^{7}$ I'm indebted to Alex Byrne (2020) for making me aware of this quotation.
} 
ever wanted." She's not alone on that judgment; until recently, the traditional definitions of woman and man were the only definitions. ${ }^{8}$

But, things change. These days, many feminist philosophers-including Bettcher herself - argue that, despite its attraction, we should reject the traditional definitions of man and woman in terms of biological sex. Indeed, if any doctrine could be considered orthodoxy in feminist philosophy, it is that there is a sex/gender distinction, i.e. that woman and man are gender terms that are not defined in terms of biological sex. The sex/gender distinction is one of the most influential ideas of the twentieth century on the broader culture, both popular and academic. Let's call this view-that man and woman are gender terms not defined in terms of sex- "the revisionary view" of gender. And we'll call the corresponding gender concepts on this view "revisionary gender concepts."

Perhaps the most influential revisionary account of gender comes from Judith Butler (1988, 1999), who has it that to be a woman is to repeatedly perform as a woman, i.e. to regularly and for the most part behave in line with feminine gender norms. ${ }^{9}$ Another prominent and revisionary view of gender was recently expressed by Elinor Burkett (2015): to be a woman is to have accrued certain experiences, endured certain indignities, and relished certain courtesies. ${ }^{10}$ Haslanger (2000, 39-42, closely following Gayle Rubin 1975) offers a definition on which to be a woman is to be systematically subordinated along some dimension (economic, political, legal, social, etc.), and "marked" as a target for this treatment by being, regularly and for the most part, observed or imagined to have bodily features presumed to be evidence of a female's

\footnotetext{
${ }^{8}$ For arguments in favor of the traditional definitions, see Alex Byrne (2020)

${ }^{9}$ Butler $(1988,527)$ says, for example, that "the 'reality' of gender is constituted by the performance itself," so that "the transvestite's gender is as fully real as anyone whose performance complies with social expectation." And, in Gender Trouble (1999, 34), she says "There is no gender identity behind the expressions of gender; that identity is performatively constituted by the very 'expressions' that are said to be its results." Clearly, then, Butler means to deny the traditional definitions of manhood and womanhood, on which they are partly constituted by biological sex (which in turn is constituted by mind-independent/"prediscursive" chromosomes, gametes, physical characteristics, hormones, and the like). Butler's view is complicated by the fact that she asks, rhetorically, "Are the ostensibly natural facts of sex discursively produced by various scientific discourses in the service of other political and social interests?" And she answers, conditionally, "If the immutable character of sex is contested, perhaps this construct called 'sex' is as culturally constructed as gender; indeed, perhaps it was always already gender, with the consequence that the distinction between sex and gender turns out to be no distinction at all" $(1999,9-10)$. So, on some readings, Butler intends to collapse the sex/gender distinction, and have it that both are performative in just the same way. But I include her in this section for two reasons. First, she clearly means to deny the traditional definitions of man and woman, taking gender not to be identical to any mind-independent ("prediscursive") characteristics of biological sex (since there is no such thing, on this reading of her view). Second, though she suggests that both sex and gender are social constructions, given that she thinks transvestites might be male-bodied and yet woman-gendered, there must be, by her own lights, a sex/gender distinction. If she really denied the sex/gender distinction and thought that being woman-gendered just is to be female-bodied, she wouldn't use the term "transvestites" here. The people she describes would simply be women, and therefore females, dressing "normally." This is because she thinks that sex is "discursively produced by various scientific discourses" (emphasis added), whereas she thinks that gender is produced by (a patriarchal) culture more broadly (cf. 1999, 11). Each has its distinctive kind of performativity, which is why there can be, to use her example, transvestites who are male-bodied but woman-gendered. See Alison Stone (2007, 70ff) for more on why, even if Butler is right that both sex and gender are social constructions, it doesn't follow that there is no sex/gender distinction on her view.

${ }^{10}$ A few of Burkett's examples: coping with the onset of one's period in the middle of a crowded subway, experiencing the humiliation of discovering that one's male work partners' checks were far larger than one's own, and experiencing the fear of being too weak to ward off rapists. One must have enough of the right kind of experiences in order to be a woman, on Burkett's view.
} 
biological role in reproduction. Katharine Jenkins (2016) suggests that womanhood is a matter of norm-relevancy: to be a woman is to take (enough) norms of femininity to be relevant to oneself (even if one does not, ultimately, abide by these norms). And, most recently, Bettcher $(2017,396)$ endorses a view on which being a woman is entirely a matter of sincere self-identification.

Now, it is important to note that there are at least two possible projects that philosophers might be engaged in when they advocate for revisionary definitions of woman and man. They might think that, as a matter of fact, womanhood and manhood are not now and never have been truly defined in part by biological sex. That is, they might think that the traditional definitions of man and woman are false, and they might be in the business of searching for the truth about womanhood and manhood. Alternatively, philosophers who advocate revisionary gender concepts might be engaged in what's become known, following Haslanger, as "ameliorative inquiry," or, more broadly, "conceptual engineering" and "metalinguistic negotiation." That is, they might think that, although our terms woman and man did - and in many linguistic communities still do-function as the traditional definitions would have it, nevertheless we should stop using the words man and woman that way, and instead come to associate those words with these new, revisionary concepts and definitions. On this view, the traditional definitions of woman and man were correct, and are correct, but the goal is to change the way we speak moving forward, for the sake of advancing the cause of social justice. While ordinary folk - those hewers of wood and drawers of water - may still use biologically-based definitions of woman and man, the idea is that social justice requires a linguistic intervention. I engage with ameliorative inquiry in other work. ${ }^{11}$ Here, in this essay, I mean to address those philosophers who hold the first view, that the traditional definitions of manhood and womanhood are now and always have been false, and who advocate revisionary gender concepts-featuring a sex/gender distinction - as the truth about womanhood and manhood.

My interest in this paper is to show that, as Lord Byron might have put it, the sex/ gender distinction has a front of brass, but feet of clay: the distinction is held in high esteem, but the arguments supporting it have surprising flaws. We will survey the literature and tour arguments in favor of the revisionary view of womanhood and manhood, and then we'll critically evaluate those arguments. I will conclude that they all fail, and so philosophers should either develop stronger arguments for the sex/ gender distinction, or cultivate a variety of feminism that's consistent with the traditional, biological understanding of manhood and womanhood.

\subsection{The Argument from Resisting Biological Determinism}

Our first argument against the traditional definitions of man and woman, and in favor of the sex/gender distinction, has to do with biological determinism, and a motivation to resist it. Toril Moi $(1999,5)$ says, "The feminists who first appropriated the sex/gender distinction for their own political purposes were looking for a strong defence against biological determinism, and in many cases the sex/gender distinction delivered

\footnotetext{
${ }^{11}$ See Bogardus (2019). There, I argue that revisionary gender concepts are either unintelligible due to vicious circularity, or trans exclusive. And I argue that the project of ameliorative inquiry is incoherent, and impossible to complete (at least, in a trans-inclusive way).
} 
precisely that." Jennifer Saul reports $(2012,196)$ : “One key reason for [the sex/gender distinction] was to draw attention to the thought that biology is not destiny: the sex we're born with needn't determine the sort of life we live." Judith Butler $(1999,8)$ agrees that the distinction between sex and gender was "[o]riginally intended to dispute the biology-is-destiny formulation..." And Mari Mikkola (2017) tells us:

The main feminist motivation for making this distinction was to counter biological determinism or the view that biology is destiny. A typical example of a biological determinist view is that of Geddes and Thompson who, in 1889, argued that social, psychological and behavioural traits were caused by metabolic state. Women supposedly conserve energy (being 'anabolic') and this makes them passive, conservative, sluggish, stable and uninterested in politics. Men expend their surplus energy (being 'katabolic') and this makes them eager, energetic, passionate, variable and, thereby, interested in political and social matters. These biological 'facts' about metabolic states were used not only to explain behavioural differences between women and men but also to justify what our social and political arrangements ought to be. To counter this kind of biological determinism, feminists have argued that behavioural and psychological differences have social, rather than biological, causes. ${ }^{12}$

Now, it's difficult to trace the dialectic in these passages. What I mean is, while it's clear that these passages contain arguments, it's difficult to discern just what the conclusion of these arguments is meant to be. On the one hand, it sounds as though we're being given a reason to accept the sex/gender distinction as true, i.e. a reason to think the traditional definitions of man and woman are false. (And that reason is that the traditional definitions somehow entail or support something known to be false: biological determinism.) Saul talks of "one key reason [for the sex/gender distinction]," and Mikkola gives us "the main feminist motivation for making this distinction." But, on the other hand, these passages can also read as though the sex/gender distinction is being deployed to "counter" biological determinism, as Mikkola puts it, to "dispute" it as Butler says, to provide "a strong defence" against it, according to Moi. And then the distinction is recommended to us as being useful in this regard, whether or not it is true. This sounds more like a pragmatic justification for adopting the sex/gender distinction: whether or not the traditional, biological definitions of womanhood and manhood are actually true, we ought to speak as though they are false, in order to prevent the spread of this pernicious doctrine of biological determinism.

Neither of these interpretations is a happy one, for our purposes, since we are looking for strong arguments for the sex/gender distinction. The first interpretation is indeed an argument for the truth of the sex/gender distinction, i.e. an argument that the traditional definitions of woman and man are false. That's good; it's one of our desiderata. However, the resulting argument is so dreadfully implausible that I'm reluctant to attribute it to any professional philosopher. The second interpretation

\footnotetext{
${ }^{12}$ For other historical and also more recent examples, see Greene (2004). Greene includes examples of this line of thinking from Steven Pinker's (2002) The Blank Slate. Pinker says, "of course the minds of men and women are not identical," and these differences "almost certainly originate in human biology." As an example of such differences, Pinker claims that boys are more violent and excel at mathematics, whereas women "experience basic emotions more intensely," and "have more intimate social relationships."
} 
involves a less implausible argument, which is good. However, this argument is not for the truth of the sex/gender distinction. At most, it is an argument for the utility of the sex/gender distinction in combating public misconceptions about biological determinism, a wouldn't-it-be-convenient-if-this-were-true sort of thought. Since we're considering the metaphysics of gender, and the truth of the traditional definitions, this interpretation of the argument is irrelevant, and therefore unsatisfying. But these are the only two interpretations that suggest themselves. And this is a major strand of contemporary feminist thought. So, I will consider both interpretations. I include these last two paragraphs in order to beg the reader's patience as we attend to two obviously unsatisfying arguments in turn.

One way of understanding the above quotations is as an argument against the traditional definitions of woman and man - and therefore in favor of the sex/gender distinction. The argument runs along these lines:

1. If women are adult female humans - if, that is, women are purely biological entities - then biological determinism is true with respect to women: a woman's social, psychological, and behavioral traits are inevitable, being determined by her biological states.

2. Biological determinism with respect to women is false.

3. So, women are not adult female humans.

And similarly with respect to men. This argument is to the point - it concludes that the traditional definitions are false- - but, as I warned you above, it isn't exactly sparkling with plausibility. Premise (1) is doing the heavy lifting here, and it's the least believable. What can we say in its favor? The idea, I take it, is that, unless we want to adopt a dualistic "ghost in the machine" view of human persons, we must admit that women (and men) are physical through and through. And this pressures us to accept that all of their characteristics are determined by their physical characteristics. This includes their responses in social situations, their psychological traits, and their behavior in general. Voila: biological determinism.

But there are good reasons to think this argument is too quick. To see this, consider another species. Though the ground in this debate is constantly shifting, at the time of writing I think we can all still agree that a lioness is simply an adult female lion. Now, does biological determinism for lionesses follow just from that? Should we conclude that a lioness' social, psychological, and behavioral traits are completely determined by her biological states merely because we know that she is an adult female lion? Wouldn't we still have to actually check?

Here's another way to see the point: premise (1) inherits its plausibility from a more general principle which says that being a biological entity (e.g. an adult female human) means biology is destiny. That's the idea behind (1): if it turns out that women are biological females, then that's sufficient for biological determinism to be true of them. So, presumably it's the being biological females that's turning the gears of this inference. But consider the fact that, of course, adult female humans have the property of being biological females. Adult female humans have the property that premise (1) says is sufficient to prove biological determinism. But then we might proceed to an unwelcome conclusion via the following argument, where $\left(1^{*}\right)$ is an instance of that more general principle that lies behind and explains the plausibility of (1) above: 
1*. If adult female humans are adult female humans, then biological determinism is true with respect to them: an adult female human's social, psychological, and behavioral traits are inevitable, being determined by her biological states.

$2 *$. Biological determinism with respect to adult female humans is false.

$3 *$. So, adult female humans are not adult female humans.

Since the argument is valid, $\left(3^{*}\right)$ is impossible, and $(2 *)$ is true, then the culprit must be $\left(1^{*}\right)$. It's false. If $\left(1^{*}\right)$ were true, then adult female humans would not escape biological determinism. And the same would go, mutatis mutandis, for adult male humans, and also for intersex individuals - every one of us has some biology, after all. This is a bad result for those who want to resist biological determinism. And, if we admit that being adult female humans is not enough for biological determinism, in order to reject $\left(1^{*}\right)$, then there's no threat of biological determinism for the traditional definition on which women are adult female humans. That is, since $\left(1^{*}\right)$ is false, and since it's an instance of the general inference that lies behind and explains premise (1) in the original argument, then that original premise (1) loses its motivation. And so that original (1)-(3) argument for the sex/gender distinction is unconvincing.

Perhaps any residual attraction of premise (1) comes from thinking that being a woman is identical with having stereotypically feminine social, psychological, and behavioral traits. Then, if having those traits - i.e. on this view, being a woman - were just a matter of biology (i.e. being female), then one could see how perhaps biological determinism might be true for women. But that understanding makes meeting those gender stereotypes essential for womanhood. And why accept that?

Let's move, then, to the second interpretation of the original arguments concerning biological determinism. This paper is concerned with the metaphysics of gender: what is a woman, and what is a man? Nevertheless, it is worth mentioning that one might think we could repair and repurpose the above argument for the sex/gender distinction by construing it instead as an invitation to engage in some conceptual engineering, i.e. as an invitation to modify, for the sake of some social good, which concepts we express with the words woman and man. The argument might proceed like this:

4. If we use woman to refer to adult female humans, then it will be too easy to think that biological determinism is true, and to justify subordination of women on that basis. $^{13}$

5. Ceteris paribus, we shouldn't allow that to be so easy.

6. So, ceteris paribus, we shouldn't use woman to refer to adult female humans.

By way of evaluation, note first that the conclusion of this argument doesn't tell us about what women are. Women may still be adult female humans, for all this argument says. This argument concludes merely that it's inappropriate, or immoral, or imprudent to say that they are. So, as I warned you above, if our question is what gender is, this argument is not to the point. The traditional definitions of woman and man may still be true, even if this argument is sound. This argument proves, at most, that it's an

\footnotetext{
${ }^{13}$ As one anonymous referee for this journal helpfully put it, perhaps the idea here is, "if we don't have two separate terms (one for the social and one for the biological) then we can't refer to the social and will end up rolling all the apparently determined traits into the one concept."
} 
unspeakable truth, or that there would be some utility in changing the subject a bit, and coming to use the words man and woman to express different concepts.

Concerning premise (4), the sexist who harbors thoughts like "women are unfit for politics because of their metabolic states" will likely also think things like "adult female humans are unfit for politics because of their metabolic states." How will conceptually engineering the terms man and woman help combat this misunderstanding? How, exactly, will conceptual engineering accomplish that social good which is meant to justify it? Why not just attack the root of the problem, and refute biological determinism instead? That's more to the point, and simple enough. But it can be done without abandoning the traditional definitions of womanhood and manhood. ${ }^{14}$ Toril Moi $(1999,5)$ makes a similar point, when she notes that "feminists managed to make a convincing case against biological determinism long before they had two different words for sex to choose from. Even in a language without the sex/gender distinction it is not difficult to convey one's opposition to the idea [of biological determinism]." ${ }^{15}$ Just so. The sex/ gender distinction is simply not required to resist biological determinism. Indeed, it's hard to see how it even helps.

\subsection{The Argument from Biologically Intersex People and Vagueness}

The second argument we'll consider against the traditional definitions of woman and man concerns the vagueness of our biological sex categories. Here's how Jennifer Saul $(2012,198)$ runs the argument:

The 'folk' view of human biological sex is that (a) there are two mutually exclusive and jointly exhaustive categories of human, male and female; (b) people fall neatly and easily into these categories. This view is false - there are people with XX chromosomes but male genitalia, people with XY chromosomes and female genitalia, people with various mixtures of male and female genitalia, and various permutations of chromosomes, genitalia, and secondary sex characteristics... So, one problem for understanding "woman" as a sex term is that intersexed people show that it is far from clear whom the sex term "woman" refers to. Consideration of intersexed people, and the way that they are often medically forced into one of our two sex categories, also helps to motivate the thought that a strict division between sex (biological) and gender (social) is not as

\footnotetext{
${ }^{14}$ For other criticisms of this sort of project of conceptual engineering, also known as ameliorative inquiry see Bogardus (2019).

15 One might convey it like so, "[The biological facts] are one of the keys to the understanding of woman. But I deny that they establish for her a fixed and inevitable destiny. They are insufficient for setting up a hierarchy of the sexes; they fail to explain why woman is the Other; they do not condemn her to remain in this subordinate role forever" (de Beauvoir [1949] 1956, 60). Ironically, though they attempt to convey the utility of the sex/gender distinction in challenging biological determinism, the quotations provided at the beginning of this section themselves provide examples of how one might challenge biological determinism without using the sex/gender distinction at all. For example, Mikkola (ibid.) says, "To counter this kind of biological determinism, feminists have argued that behavioural and psychological differences have social, rather than biological, causes." But of course one might argue in precisely that same way, while holding that men are adult human males and women are adult human females.
} 
tenable as it may have seemed. Sex is arguably, at least in part and in some cases, socially determined. ${ }^{16}$

Saul means to argue against the view that, as she puts it, man and woman are "sex terms." I myself don't think the traditional definitions of woman and man are best described as "sex terms," because, while biological sex is a crucial part of the traditional definitions of man and woman, those definitions also include information about age and species. (Merely being female isn't enough to be a woman, otherwise newborn female humans would be women, as would female fruit flies.) By "sex term," Saul seems to mean a term that is defined at least in part by biological sex. Bearing this caveat in mind, I believe Saul's argument goes like so:

7. If man and woman are sex terms, then any adult human is either clearly a man or clearly a woman and not both.

8. But some adult intersex people are neither clearly men nor clearly women.

9. So, man and woman are not sex terms.

There are problems. What premise (7) says, substantially, is that if two terms are sex terms, then, for any human, exactly one of the terms clearly applies- "neatly and easily" as Saul puts it. But that's doubtful. Against premise (7), consider that a similar argument, swapping out man and woman for male and female, would show that male and female are not sex terms. But that's absurd. I'm thinking of this argument:

7*. If male and female are sex terms, then any human is either clearly a male or clearly a female and not both.

8*. But some intersex people are neither clearly male nor clearly female.

9*. So, male and female are not sex terms.

Premise $\left(7^{*}\right)$ is an instance of the general principle embodied by the original premise (7). And premise $(8 *)$ is at least as plausible as the original premise (8): at least some intersex individuals do not fall "neatly and easily" into biological sex categories, just as with gender categories. Yet conclusion $\left(9^{*}\right)$ is absurd. So, what's gone wrong? I suggest the problem is premise ( $\left.7^{*}\right)$.

\footnotetext{
${ }^{16}$ One finds similar arguments in Dembroff (2018), Bettcher $(2009,103)$, and again in Bettcher $(2013,236)$. Elizabeth Barnes $(2019,16)$ puts it this way: "The prevalence of intersex conditions seems to be enough to show that our gender terms are not simple synonyms for biological sex terms - even if ordinary speakers often take them to be. Research increasingly shows a spectrum of sex variation between the male and female binaries. But ordinary speakers seem happy to attribute terms like 'man' or 'woman' to people with various intersex conditions, so long as their gender expression and presentation is binary and has been consistent throughout their life." I believe Barnes is right that (many) ordinary speakers seem happy to treat at least some intersex individuals as men or women, including calling them such. But Barnes' version of the argument assumes that these ordinary speakers are not equally happy to treat these intersex individuals as male or female as well, including calling them such. For, if they are so willing, Barnes has found no discrepancy between our use of gender terms and our use of biological sex terms. And ordinary speakers may well be so willing, perhaps because they do not mean to use either gender or biological sex terms in a literal way in these cases, but rather in an honorific, courteous way. Without ruling out this possibility, Barnes' version of the argument does not succeed.
} 
Somehow our sex terms male and female allow for borderline cases. Probably because we don't really think any person is either clearly male or clearly female and not both, as premise $(7 *)$ suggests. ${ }^{17}$ Saul is incorrect to say that it's part of the folk view of human biological sex that everyone falls "neatly and easily" into one or the other sex category, just as it's no part of the folk view of "bald" that anyone you choose falls "neatly and easily" into the bald or the non-bald camp. An astonishing number of our concepts allow for borderline cases.

And, so, the advocate of the traditional definitions of woman and man is free to deny the original premise (7) on the same grounds: perhaps woman and man are defined partly in terms of sex, and perhaps that's partly why those terms allow for borderline cases. After all, many biological concepts allow for borderline cases. Like the central biological concept life, for example. Think of viruses, or prions. And also fish (think lungfish), eye (think eye-spots), etc. When it comes to our concept woman, female is vague, but so are adult and human. So, if a woman is an adult female human, it should be no surprise that woman allows for borderline cases. That concept plausibly inherits its vagueness from its constituent concepts, all of which are vague. But why think this vagueness is a problem? Biology is shot through with vagueness, after all. There's no way around it. ${ }^{18}$

What's more, revisionary gender concepts are themselves vague. The gender revisionist agrees there can be borderline cases of sex as well as borderline cases of gender; we're often told "gender is a spectrum," after all. Review again those revisionary proposals we canvassed a moment ago: Butler's performativity view; Burkett's right-kind-of-experience view; Haslanger's subordination-on-basis-of-sex view; Bettcher's sincere self-identification view; and Jenkins' accepting-enough-of-the-right-kind-of-gender-norms view. Each one of these will allow for borderline cases. If that vagueness doesn't discredit these revisionary views, why should it discredit the traditional definitions? If vagueness is a problem, gender revisionism doesn't solve it. In fact, by believing in both sex and gender categories as distinct, and by adding more gender categories that are less well-defined, gender revisionism piles vagueness upon vagueness. It compounds the problem. So, if vagueness is a cost, gender revisionism has a higher price than do the traditional definitions of man and woman. We have here, then, no reason to reject the traditional definitions. $^{19}$

\footnotetext{
${ }^{17}$ Perhaps you think any human is either male or female and never both, while still being skeptical that it's always clear which of those categories a person is in. I mean to express only that latter skepticism, while remaining neutral on whether every human is either male or female and never both.

${ }^{18}$ As de Beauvoir ([1949] 1956, 52) put it, "In nature, nothing is ever perfectly clear."

${ }^{19}$ For another, helpful response to the argument from intersex individuals and vagueness, please see Alex Byrne (2020).
} 


\subsection{An Argument from the Normativity of Gender}

Robin Dembroff (2018) recently presented the following argument against "the identity view of gender," i.e. against what I've been calling the traditional definitions of man and woman:

For all the huffing about how gender is just body parts, no one in practice holds the identity view of gender. If gender is just reproductive features and nothing more, it makes no more sense to insist that people must look, love or act in particular ways on the basis of gender than it would to demand that people modify their behaviour on the basis of eye colour or height. Even if reproductive traits are correlated to personality, physical capabilities or social interests, such correlations don't equate to norms. As David Hume has taught us, is doesn't make ought. Having feet is correlated with walking, but I can walk on my hands if I want to. Having a tongue is correlated with experiencing taste, but who cares if I decide to drink Soylent every day? Once we recognise that gender categories mark how one ought to be, and not only how one's body is, the identity view unravels. To build in the 'oughts' is to admit that gender is more than just body parts.

I believe that Dembroff is reasoning like so:

10. Gender properties like being a man and being a woman entail how one ought to be. They have normative implications.

11. Biological properties like being an adult human male and being an adult human female do not entail how one ought to be. They have no normative implications.

12. So, gender properties cannot be identical with biological properties. In particular, the traditional definitions of woman and man cannot be true.

The inference here looks to operate via Leibniz' Indiscernibility of Identicals. If the property of being a woman is identical with the property of being an adult female human, then whatever is true of being a woman must also be true of being an adult female human, and vice versa. But there are differences, Dembroff thinks: being a woman has normative implications, but being an adult human female does not. So, these properties cannot be identical. (And similarly with the traditional definition of man.) QED.

That main inference is indeed valid. Unfortunately, there are reasons to doubt the truth of premise (11). As a warm-up exercise, notice that we are often quite comfortable attributing normativity to purely biological entities: the heart should pump blood, the eye should focus, the pancreas should produce insulin, and so on. Now, you might think that these are "proper function oughts," not true moral oughts, and perhaps Dembroff has in mind only moral oughts for the purposes of this argument. But, in fact, it does looks like purely biological entities are also amenable to full-blown moral oughts. Adult human males ought to protect those in their care, for example, and they shouldn't be wantonly cruel. Adult human males and females both ought to be kind and generous. Adult human females should not 
be oppressed. These are normative truths we're in a position to know solely by reflecting on our biological concepts of adult human males and adult human females.

Here's another way to put it: if all you know of a thing is that he is an adult human male, you are in a position to know various normative facts about him; those normative facts are knowable solely by reflection upon one's concepts. You're not left wondering, for example, whether this adult human male ought to be enslaved; you're in a position to know he shouldn't be, given only the information that he's an adult male human. And likewise with females. This shows that there are a priori entailment relations between our concepts of adult human females and males, on the one hand, and our moral concepts, on the other, presumably because there are entailment relations between the relevant mind-independent properties, and we're tracking these with our concepts. This is contrary to Dembroff's premise (11). ${ }^{20}$

So, it seems as though we do in fact "build in the oughts" to categories like adult male human and adult female human, using Dembroff's terminology. Those biological categories are not normatively sterile but indeed do have normative implications, contrary to premise $(11) .^{21}$ It's not at all surprising then, on the traditional view, that our categories of man and woman are also normatively fecund. Far from unraveling the traditional definitions of man and woman, therefore, Dembroff's observation is exactly what one would expect on the traditional view. But, if so, Dembroff's argument against the traditional view fails.

\footnotetext{
${ }^{20}$ Even Judith Butler $(1993,1)$ agrees: "The category of 'sex' is, from the start, normative; it is what Foucault has called a 'regulatory ideal'." Now, this normative fecundity of sex is less plausible when it comes to at least some purely social norms that "insist that people must look, love or act in particular ways," as Dembroff puts it. If we have in mind norms about, for example, shaving legs, it's not very plausible that our concept of being an adult human female "marks," as Dembroff says, that such a one must shave her legs. (Or, if you prefer to put the argument in terms of properties, it's implausible that the property of being an adult human female necessitates the normative property of being obligated to shave one's legs.) So if our concept of being a woman did "mark" that such a one must shave her legs (and likewise with the corresponding properties), Dembroff's argument would be on firmer footing. However, though it is indeed implausible that there are conceptually necessary connections between being an adult human female and being socially obligated to shave one's legs, it's implausible to precisely the same degree that there are such connections between our concept of being a woman and being socially obligated to shave one's legs. (And likewise, mutatis mutandis, for the relevant properties.) The proof is that our concept of womanhood can survive societal changes in legshaving norms. The norm concerning leg-shaving is eroding, and may soon disappear. And yet, even so, we may well continue to use our concept of womanhood. We can easily imagine without contradiction, that is, a situation in which women are not socially obligated to shave their legs. So, it's not essential to our concept of womanhood that such a one must shave her legs. But, if that's right, our concept of womanhood is on a par with our concept of being an adult human female: neither one has these sorts of social 'oughts' "built in," as Dembroff puts it. (And likewise, mutatis mutandis, for the relevant properties. And similarly if we interpret the argument in terms of moral obligations.) Or, at least, that's how things will seem to anyone exercising the traditional concept of womanhood, in which case she'd be well justified in rejecting Dembroff's argument.

${ }^{21}$ Dembroff alludes to David Hume's is/ought gap. But I can't see how this is relevant here. If one is worried about basing normative judgments on descriptions, including those concerning biological categories, one should also worry about basing normative judgments on descriptions concerning gender categories. If you can't get an ought from descriptions of sex, then you can't get an ought from descriptions of gender. Dembroff seems to think there is no barrier deriving oughts from descriptions of gender, but then what's the objection to deriving oughts from descriptions of biological sex?
} 


\subsection{Arguments from Thought Experiments}

John Corvino $(2000,174)$ offers the following argument against the traditional definitions of woman and man:

[S] uppose you were to discover that your chromosomal structure is quite different than you expected. That is, if you are a woman suppose you were to discover it to be XY; if you are a man suppose you were to discover it to be XX - and that your various sexual characteristics were in fact expert surgical constructions performed at birth. I contend that you would not cease being a woman or a man: the various other characteristics we associate with gender overrule the biological in this case. So gender is not identical with biological sex.

There are real life examples of cases like this. David Reimer, for example, was raised as a girl after a botched circumcision. While he was a small child, surgery and hormone therapy were applied in order to transition him to female. When he was 14 years old, he learned what had happened to him, and he decided to transition back to male and live as a boy/man. ${ }^{22}$

Returning to the argument, it looks as though Corvino means for me to reason this way $^{23}$ :

13. If gender is identical with biological sex, ${ }^{24}$ then: if I were to discover that I had XX chromosomes, then I would be a woman.

14. But I would not be a woman even if I were to discover that I had XX chromosomes.

15. So, gender is not identical with biological sex.

There are reasons to be concerned about this argument. Let's start with premise (13). As I said earlier in the paper, on the most plausible understanding of the traditional definitions of man and woman - or at least the one I'm interested in defending - one's biological sex is not determined only by one's genetics. Perhaps the scientific essence of biological sex simply has to do with gamete size. Or perhaps it's a matter of weighing several criteria like genetics, gamete size, one's hormone levels, and one's primary and secondary sex characteristics, according to how central or crucial we take them to be to membership in a biological sex category. ${ }^{25}$ But, if that's the case, then the simple genetic change Corvino asks us to consider in his thought experiment needn't make it obvious that one's sex has changed. And, so, even on the traditional definitions of manhood and womanhood, we needn't expect this merely genetic change to make it obvious that one's gender has changed. This is sufficient reason to reject premise (13).

\footnotetext{
${ }^{22}$ You can read more about the tragic case of David Reimer in Colapinto (2006).

${ }^{23}$ I'll run the argument in the first-person, for my own case, but the reader should make changes appropriate to his or her case.

${ }^{24}$ I'm using Corvino's language here, but, as I said above, I don't think the traditional definitions of woman and man are best expressed by saying "gender is identical to biological sex." Biological sex is a crucial part of the definition of gender, but the definition also includes information about age and species.

${ }^{25}$ Perhaps we do something similar with each of the other biological categories mentioned above, like "life," "adult," and "human."
} 
So, Corvino's argument against the traditional definitions of man and woman is not sound; it doesn't give us reason to doubt the traditional definitions. In fact, it's worth noticing that Corvino's thought experiment actually points in the opposite direction, lending support to the traditional definitions of woman and man. For notice this: if gender isn't defined even partly in terms of biological sex, if sex and gender are conceptually distinct, then changing your genetics would not be relevant to the question of whether you're a man or a woman. But it seems relevant, doesn't it? You have to think about Corvino's case a bit, don't you? That's a reason to think sex and gender are not distinct, a reason to believe that sex is in fact conceptually connected to gender.

Finally, against Corvino's premise (14), I'm fairly inclined to think that I would find out, in that case, that I am a woman. And perhaps you're inclined that way as well. David Reimer found out that his chromosomal structure was XY, as Corvino would say, and Reimer judged on that basis that he was a boy/man. He may well have been right. Even a mild inclination in that direction is hard to explain on the view that sex and gender are distinct, but easy to accommodate on the traditional definitions, according to which genetics and biological sex are closely related, and according to which biological sex and gender are constitutively related. So, Corvino's argument cannot bear the weight of the sex/gender distinction.

Next, let's consider another argument from a thought experiment, this time from Talia Mae Bettcher (2009, 103). Bettcher targets what she calls "the definitional account" of gender terms, which is the conjunction of what we've labeled "the traditional definitions" of man and woman. Bettcher reasons this way:

A second problem is that this definitional account omits the cultural role of woman, and the conceptions and practices related to that role. ${ }^{26}$ We can imagine a world where the cultural roles normally assigned on the basis of sex are inverted: females dress "like men," males dress "like women"; stereotypical traits and behaviors are assigned to each group. Here, it isn't clear how to apply the terms "man" and "woman." Does physical sex or cultural role determine category membership? If this is a hard case (I believe it is), then cultural roles (and related practices and conceptions) must somehow be connected to the semantic content of gender terms like "woman."

I take it that Bettcher is reasoning in the following way:

16. If the cultural roles normally assigned on the basis of sex were inverted, then it wouldn't be clear (from our actual perspective) how to apply the terms man and woman.

17. Therefore, the cultural roles (and related practices and conceptions) must somehow be connected to the semantic content of terms like woman.

18. Therefore, the traditional definitions of woman and man are false: there's more to womanhood than just being an adult female human, and similarly with manhood.

\footnotetext{
${ }^{26}$ If this is "a second problem," perhaps you're curious what the first problem is meant to be. Bettcher (ibid, 103) makes trouble for some definitions of biological sex, concluding that "the term 'sex' does not itself seem very easy to define." Since this is similar enough to the argument from vagueness above, I omit it here.
} 
In endorsing premise (16), it seems as though Bettcher is going in for something like a descriptivist view of gender terms, privileging certain superficial, functional features of a kind when applying the name of that kind. Some terms function that way. For example, we can think of the category picked out by "golden" (i.e. "gold-colored"). To be in that category, a thing need only have the right superficial features. Or think of the category picked out by "mousetrap." There, category membership is determined entirely by a thing's functional role, and not its internal constitution. For both "golden" and "mousetrap," what the thing is doesn't really matter. What matters is merely how it looks, or how it functions.

But, as Saul Kripke (1980) famously argued, not all of our kind terms function this way. Some are "rigid designators," preserving reference across all worlds where the referent exists. Consider natural kind terms like "gold" and "mouse." Gold need not be golden; it needn't have any of the superficial or functional features we commonly associate with gold. What's necessary and sufficient is being atomic number 79; that scientific essence is designated rigidly by our natural kind term "gold." Similarly with "mouse." A mouse need not look like a typical mouse, nor function like one. What's necessary and sufficient is a certain genetic structure and evolutionary history; that scientific essence is designated rigidly by our natural kind term "mouse."

On the traditional view, man and woman - as well as male and female - are natural kind terms, and rigid designators of what's sometimes called a "hidden" or "scientific" essence. Bettcher herself seems to use biological sex terms as rigid designators, when she describes her scenario as one in which "females dress 'like men"" and "males dress "like women'." Even though the people she calls "females" in this scenario are superficially and functionally very unlike the people we call "females," Bettcher still describes them as "females." Presumably because these people share some internal scientific essence that Bettcher takes "female" to designate. (And likewise with "male.") Apparently, that strikes Bettcher as the obvious, natural way to describe the situation: females dressing like men, etc. I agree.

Now, on the traditional view, something similar will be said about this situation with regard to gender terms like woman and man. Bettcher's scenario is one in which men dress and behave as women actually do, and women dress and behave as men actually do. That seems to me to be the obvious, natural way of describing the situation. I certainly see no infelicity in that description, as one might sense an infelicity in statements like "my golden chalice is a lovely shade of red" 27 or "this mousetrap was not designed to and indeed is completely unable to catch any mice."

Since no support was given for premise (16), and since it is clearly inconsistent with a natural interpretation of Bettcher's thought experiment on the traditional definitions of man and woman, I conclude that Bettcher's argument for the sex/gender distinction does not move the needle. That is, advocates of the traditional definitions will deny her interpretation of her case, and in a natural, non-ad-hoc way. They'll think it is in fact clear how to apply our woman and man in the case as described, since it's clear how to apply our sex terms (as Bettcher herself grants), together with our age and species terms. Somewhat puzzingly, in a later objection to a Wittgensteinian analysis of gender terms, Bettcher (ibid., 104) says, "when the natural attitude prevails, physical sex

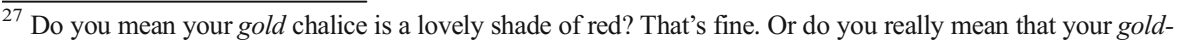
colored chalice is colored red? Not so fine. (Infelicitous; impossible.)
} 
strictly determines the application of gender terms such as 'woman'." Yes, just so. But, therefore, anyone in the grip of the traditional definitions of man and woman will find it clear how to apply gender terms in the case Bettcher describes, contrary to what premise (16) asserts.

And we needn't reason from the theory to the particular judgment in this case. We can do our best to make a theory-independent concrete judgment. Just ask yourself: spelling out the details as you like, could there be any scenario in which men dress, behave, and socially function the way that women actually do ${ }^{28}$ And vice versa? To the degree you think the answer is obviously "yes," you should reject premise (16) and allow that Bettcher's argument against the traditional definitions of woman and man fails. In my own case, I think that the answer is obviously "yes," and so I conclude that premise (16) is false, and Bettcher's argument fails.

Before wrapping up, let's pause to look at a second argument that Bettcher offers (ibid., 104):

Second, consider adjectives such as "womanly," "manly," "girly," and the like. It seems as if they have cultural traits packed right into their meaning. When somebody says, "Well, no. That's a bit too girly for me, I'm afraid," we shouldn't expect them to be complaining about having to dig ditches. To be sure, one might argue that such adjectives really mean only "like a woman" and "like a girl" (where the current cultural facts are extraneous to the content). However, it does seem that in the case of the world imagined above, the very meaning of the word would have changed, if "girly" should be a good way to describe ditch digging. So it again seems that cultural roles assigned on the basis of sex are part of the semantic content. And this suggests that there is something wrong with this definitional account of gender.

Bettcher's reasoning here goes something like this:

19. If the cultural roles normally assigned on the basis of sex were inverted, then girly would accurately describe, for example, ditch digging.

20. If girly would accurately describe ditch digging in that scenario, then the very meaning of the word would have changed.

21. Therefore, the cultural roles (and related practices and conceptions) must somehow be connected to the semantic content of gender adjectives like girly.

22. Therefore, the traditional definitions of woman and man are false: there's more to womanhood than just being an adult female human, and similarly with manhood.

I have doubts about premise (20). I suspect there's an ambiguity lurking here, and some distinctions might help us keep things clear. Girly plausibly does mean "like a girl." But, to account for the possibility that girls might behave differently in different contexts, we might put the meaning a bit more carefully as "like, characteristic of, or appropriate to girls around here." And if that's right, then girly will inherit features from that indexical element here. It

\footnotetext{
${ }^{28}$ You might sneak up on this question by first reflecting on Shakespearean plays, with male actors playing the roles of women, and then "expanding out" from there, to include complete social function. I'm grateful to an anonymous referee for this suggestion.
} 
will function with what has become known, following Kaplan (1989), as a "character" and a "content." Bettcher's talk of "the very meaning of the word" is, I think, ambiguous between these two sorts of meaning. The content is the particular referent, or extension, of a term. This can vary from context to context, just as here picks out different places in different contexts of use. The character, on the other hand, is invariant across contexts, and is a mapping from particular uses of the term to a particular referent, or extension-a function taking contexts as input and delivering contents as output.

So, as used by us around here in the actual world, the character of girly takes us to the familiar extension of stereotypically girly traits, activities, and the like. Digging ditches is not in that extension. But, in the gender-inverted scenario that Bettcher describes, the character of girly takes us to a radically different extension, one which includes digging ditches. So far, so good.

Now, premise (20) alleges that this change of content would be a change in "the very meaning of the word," and in a way that - according to the inference to (21) - requires that cultural roles be "connected to the semantic content" of girly. But I think we can now see that this is not so. While the content - the extension — does indeed change, the character - what some philosophers call "the linguistic meaning" of the term-remains constant. And that character of girly - that mapping from contexts to extensions - may well function as the traditional definitions would have it, with no connection to, as Bettcher puts it, cultural roles, practices, or conceptions. That is, it may function in something like the following way: to find the girly things in some context of utterance, find those things that are like, characteristic of, or appropriate to (young) female human beings in that context. Girls remain young female humans. No appeal to cultural roles is required.

So, Bettcher's argument faces a dilemma. The first option is that premise (20) is true in virtue of the content of girly changing. But, on this option, premise (21) doesn't follow, since cultural roles, practices, and conceptions need not be part of either the character or the content of girly in order to explain this change of content. ${ }^{29}$ The second option is that premise (20) is false, because there is no one meaning of girly that answers to "the very meaning of the word," and the best candidate - the character of the term - plausibly remains constant through Bettcher's thought experiment, contrary to what premise (20) asserts. So, either Bettcher's argument features a false premise, or an invalid inference. Either way, it fails to refute the traditional definitions of woman and man.

\section{Conclusion}

It's widely believed in contemporary feminist philosophy that there is a sex/gender distinction, that manhood and womanhood are social constructs, that, for example, to be a woman is not to be an adult female human. This view is more often assumed and asserted than argued for. And what we've seen in this paper is that the enthusiasm with which this doctrine is asserted is all out of proportion to the strength of the arguments in its favor. So, there remains much work for philosophy to do, either to develop stronger arguments against the traditional definitions of woman and man, or to develop a variety of feminism on the foundation of this traditional, biological understanding of manhood and womanhood.

\footnotetext{
${ }^{29}$ Just as, when "here" picks out Malibu, it doesn't follow that wildfires, mudslides, and movie stars must somehow be connected the "the semantic content" of the word "here."
} 


\section{References}

Antony, L. (1998). 'Human nature' and its role in feminist theory. In J. Kourany (Ed.), Philosophy in a feminist voice. New Haven: Princeton University Press.

Barnes, E. (2019). Gender and Gender Terms1. Nous. https://doi.org/10.1111/nous.12279.

Bettcher, T. M. (2009). Trans identities and first-person authority. In L. Shrage (Ed.), You've changed: Sex reassignment and personal identity (pp. 98-120). Oxford University Press.

Bettcher, T. M. (2013). Trans women and the meaning of 'woman'. In A. Soble, N. Power, \& R. Halwani (Eds.), Philosophy of sex: Contemporary readings (6th ed., pp. 233-250). Rowan \& Littlefield.

Bettcher, T. M. (2017). Through the looking glass. In A. Garry, S. Khader, \& A. Stone (Eds.), Routledge companion to feminist philosophy. New York: Routledge.

Bogardus, T. (2019). Some Internal Problems with Revisionary Gender Concepts. Philosophia. https://oi. org/10.1007/s11406-019-00107-2.

Brison, S. J. (2003). Beauvoir and feminism: interview and reflections. In C. Card (Ed.), The Cambridge companion to Simone de Beauvoir. Cambridge: Cambridge University Press.

Burkett, E. (2015, June). What makes a woman? New York Times Sunday Review, 6, 2015.

Butler, J. (1988). Performative acts and gender constitution: an essay in phenomenology and feminist theory. Theatre Journal, 40(4), 519-531.

Butler, J. (1993). Bodies that matter: On the discursive limits of "sex". New York: Routledge.

Butler, J. (1999). Gender trouble (2nd ed.). London: Routledge.

Byrne, A. (2020). Are Women Adult Human Females? Philosophical Studies. https://doi.org/10.1007/s11098019-01408-8.

Colapinto, J. (2006). As nature made him: The boy who was raised as a girl (2nd ed.). New York: Harper Perennial.

Corvino, J. (2000). Analyzing gender. Southwest Philosophy Review, 17(1), 173-180.

de Beauvoir, Simone [1949] (1956). The Second Sex, translated by H.M. Parshley (New York: Vintage Books).

Dembroff, R. (2018). Why be nonbinary? Aeon. Published: October 30, 2018. Available at: https://aeon. co/essays/nonbinary-identity-is-a-radical-stance-against-gender-segregation. Accessed 10 Jan 2019.

Gatens, M. (1996). Imaginary bodies. London: Routledge.

Green, R. (2010). Robert Stoller's sex and gender: 40 years on. Archives of Sexual Behavior, 39(6), 14571465.

Greene, S. (2004). Biological determinism: Persisting problems for the psychology of women. Feminism and Psychology, 14, 431-435.

Grosz, E. (1994). Volatile bodies: Toward a corporeal feminism. Bloomington: Indiana University Press.

Hale, J. (1996). Are lesbians woman? Hypatia, 11(2), 94-121.

Haslanger, S. (2000). Gender and race: (What) are they? (what) do we want them to be? Noûs, 34(1), 31-55.

Haslanger, S. (2012). Resisting reality. New York: Oxford University Press.

Heinämaa, S. (1997). What is a woman? Hypatia, 12(1), 20-39.

Jenkins, K. (2016). Amelioration and inclusion: Gender identity and the concept of Woman. Ethics, 126, 394 421.

Kaplan, D. (1989). Demonstratives. In Almog, Perry, \& Wettstein (Eds.), Themes from Kaplan (pp. 481-563). Oxford: Oxford University Press.

Kirkpatrick, K. (2019). Becoming beauvoir: A life. New York: Bloomsbury Academic.

Kripke, S. (1980). Naming and necessity. Harvard University Press.

Lorber, J. (1994). Paradoxes of gender. New Haven: Yale University Press.

Mikkola, M. (2016). The wrong of injustice: Dehumanization and its role in feminist philosophy. Oxford: Oxford University Press.

Mikkola, M. (2017). Feminist perspectives on sex and gender. In The Stanford encyclopedia of philosophy. https://plato.stanford.edu/entries/feminism-gender/. Cited 3 February 2018.

Moi, T. (1999). What is a woman? Oxford University Press.

Money, J. (1955). Hermaphroditism, gender and precocity in hyperadrenocorticism: Psychologic findings. Bulletin of the Johns Hopkins Hospital, 96, 253-264.

Money, J., \& Ehrhardt, A. A. (1972). Man and woman, boy and girl. Baltimore: Johns Hopkins University Press. 
Nicholson, L. (1994). Interpreting gender. Signs, 20, 79-105.

Pinker, S. (2002). The blank slate: The modern denial of human nature. London: Allen Lane.

Prokhovnik, R. (1999). Rational woman. London: Routledge.

Rubin, G. (1975). The traffic in women: Notes on the 'political economy' of sex. In R. Reiter (Ed.), Toward an anthropology of women. New York: Monthly Review Press.

Saul, J. (2012). Politically significant terms and philosophy of language: Methodological issues. In A. Superson \& S. Crasnow (Eds.), Analytic feminist contributions to traditional philosophy. Oxford University Press.

Stoljar, N. (1995). Essence, identity and the concept of woman. Philosophical Topics, 23, 261-293.

Stoller, R. (1968). Sex and gender: On the development of masculinity and femininity. New York: Science House.

Stone, A. (2007). An introduction to feminist philosophy. Cambridge: Polity Press.

Young, I. (1997). Gender as seriality: Thinking about women as a social collective. In I. M. Young (Ed.), Intersecting voices. Princeton: Princeton University Press.

Publisher's Note Springer Nature remains neutral with regard to jurisdictional claims in published maps and institutional affiliations.

\section{Affiliations}

\section{Tomas Bogardus ${ }^{1}$}

1 Religion and Philosophy Division, Pepperdine University, 24255 Pacific Coast Hwy, Malibu, CA 90263, USA 